\title{
Sitagliptin Improves the Impaired Acute Insulin Response during a Meal Tolerance Test in Japanese Patients with Type 2 Diabetes Mellitus: A Small-Scale Real-World Study
}

\author{
Tsuyoshi Ohkura • Youhei Fujioka · Keisuke Sumi • Risa Nakanishi • \\ Hideki Shiochi $\cdot$ Naoya Yamamoto $\cdot$ Kazuhiko Matsuzawa $\cdot$ Shoichiro Izawa \\ Hiroko Ohkura $\cdot$ Masahiko Kato $\cdot$ Shin-ichi Taniguchi $\cdot$ Kazuhiro Yamamoto \\ To view enhanced content go to www.diabetestherapy-open.com \\ Received: April 3, 2014 / Published online: June 3, 2014 \\ (C) The Author(s) 2014. This article is published with open access at Springerlink.com
}

\section{ABSTRACT}

Introduction: Several studies have shown that dipeptidyl peptidase-4 (DPP-4) inhibitors improve insulin secretion during oral glucose tolerance tests. However, the effects of DPP-4 inhibitors on impaired acute insulin responses in the postprandial state in real-world settings are unknown. Therefore, we evaluated the effects of sitagliptin on the acute insulin responses in Japanese patients with type 2 diabetes mellitus (T2DM) using meal tolerance tests.

Trial registration: University hospital Medical Information Network identifier \#UMIN000011189.

Electronic supplementary material The online version of this article (doi:10.1007/s13300-014-0071-1) contains supplementary material, which is available to authorized users.

T. Ohkura $(\bowtie) \cdot$ Y. Fujioka $\cdot$ K. Sumi .

R. Nakanishi $\cdot$ H. Shiochi · N. Yamamoto ·

S. Izawa $\cdot$ M. Kato $\cdot$ K. Yamamoto

Division of Cardiovascular Medicine, Endocrinology

and Metabolism, Department of Molecular

Medicine and Therapeutics, Tottori University

Faculty of Medicine, Yonago, Tottori, Japan

e-mail: ohkura@med.tottori-u.ac.jp

K. Matsuzawa $\cdot$ H. Ohkura $\cdot$ S. Taniguchi Department of Regional Medicine, Tottori University Faculty of Medicine, Yonago, Tottori, Japan
Methods: Twenty-one patients with T2DM were given a test meal (460 kcal), and plasma glucose and insulin were measured at $0,30,60$, 120, and $180 \mathrm{~min}$ after the meal. The insulinogenic index of all of these patients was below 43.2. The postprandial profiles were assessed at baseline and after 3 months of treatment with $50 \mathrm{mg} /$ day sitagliptin after a meal $(n=11)$ or were untreated (control group; $n=10$ ). This study was a prospective, openlabel, non-blinded, non-randomized, clinical study.

Results: Sitagliptin significantly decreased the plasma glucose levels at 60, 120, and $180 \mathrm{~min}$, and significantly increased the plasma insulin levels at 0 and $30 \mathrm{~min}$. There were no significant changes in glucose or insulin in the control group. The insulinogenic index increased significantly in the sitagliptin group compared with the control group $(+16.7$ vs. +0.1 , $P<0.005)$. However, homeostasis model assessment of insulin resistance and the insulin sensitivity index were not significant different between the two groups.

Conclusion: Administration of sitagliptin at $50 \mathrm{mg} /$ day after a meal improved the impaired acute insulin response and suppressed 
postprandial hyperglycemia. Whereas the study is rather small and the design is suboptimal as it is not randomized and not blinded, these results suggest that sitagliptin is effective in Japanese patients with T2DM, many of whom display impaired acute insulin responses after a meal.

Keywords: Dipeptidyl peptidase-4 (DPP-4) inhibitor; Insulinogenic index; Japanese; Meal tolerance test; Plasma glucose; Plasma insulin; Real world; Sitagliptin; Type 2 diabetes mellitus

\section{INTRODUCTION}

Type 2 diabetes mellitus (T2DM) is a heterogeneous disease characterized by insulin resistance and defective insulin secretion [1]. Defective insulin secretion is perhaps the most important pathophysiologic feature of T2DM. Several dipeptidyl peptidase-4 (DPP-4) inhibitors are available for the treatment of T2DM [2]. DPP-4 inhibitors work by inhibiting DPP-4, which degrades incretin hormones such as glucagon-like peptide (GLP)-1 and glucosedependent insulinotropic polypeptide, stabilizing the intact (active) forms of the hormones [3]. DPP-4 inhibitors were first reported to improve glycemic control, insulin secretion, and $\beta$-cell function in rodents [4]. In patients with T2DM, DPP-4 inhibitors were reported to decrease postprandial glucose excursions, fasting plasma glucose (FPG), and hemoglobin A1c (HbA1c), without affecting insulin levels [5]. In another study, sitagliptin significantly increased insulin levels (21-22\%) and decreased glucagon levels (7-14\%) at $2 \mathrm{~h}$ in an oral glucose tolerance test (OGTT) relative to placebo, but the acute insulin response (30 min) was not significantly increased [6]. Other studies have also demonstrated that postprandial insulin and C-peptide levels were not significantly affected by sitagliptin [7]. In that study, the sensitivity of pancreatic $\beta$ cells to glucose, evaluated as C-peptide at $0 \mathrm{~min}(\mathrm{CP} 0) /$ plasma glucose at 0 min (PG0) and CP30/PG30, did not improve in the sitagliptin or control groups, but CP240/PG240 increased in the sitagliptin group with borderline statistical significance. Another study showed that vildagliptin lowered postprandial glucagon levels by $16 \%$, and that insulin sensitivity and glucose clearance, as determined using glucose clamps, were improved by vildagliptin, but the postprandial insulin levels did not change [8]. The mean body mass index (BMI) of patients in these studies was $27.5 \mathrm{~kg} / \mathrm{m}^{2}$ [5], $29.5 \mathrm{~kg} / \mathrm{m}^{2}$ [6], $33.2 \mathrm{~kg} / \mathrm{m}^{2}$ [7], and $31.4 \mathrm{~kg} / \mathrm{m}^{2}$ [8]. Therefore, these results suggest that DPP-4 inhibitors mainly improved insulin resistance in obese populations, with no or only small improvements in the acute insulin response.

In Japan, approximately half of all patients with diabetes have a genetic predisposition to the disease, and insulin secretion is often impaired in lean patients with diabetes mellitus [9, 10]. Additionally, Japanese and Asian patients often show reduced $\beta$-cell function and it is thought that the innate insulin secretory capacity of East Asians is limited [11, 12]. The possible instability and vulnerability of canalization due to reduced $\beta$ cell function may contribute to the increased prevalence of diabetes in East Asia in recent decades.

A prior study of Japanese patients revealed that once-daily administration of 100-mg sitagliptin for 12 weeks improved the insulinogenic index compared with placebo during a MTT in which the subjects consumed two nutritional bars and a nutritional drink [13]. However, that study was a phase 2 trial, and sitagliptin was administered before a meal at a dose of $100 \mathrm{mg} /$ day. In Japan, the package 
insert for sitagliptin recommends a dose of $50 \mathrm{mg} /$ day [14]. Therefore, the effects of a standard dose of sitagliptin (50 mg/day) on the postprandial metabolic control of patients in real-world settings are currently unknown. Furthermore, Japanese patients usually take sitagliptin after a meal in accordance with the package insert, which is based on the results of peak concentration time $\left(T_{\max }\right)$ and apparent terminal half-life $\left(t_{1 / 2}\right)$ that were not altered significantly by food [15]. Based on these results, we conducted a study to determine whether a standard dose of sitagliptin $(50 \mathrm{mg}$ / day) after a meal could improve the impaired acute insulin response in Japanese patients with T2DM in a real-world setting. We used a meal tolerance test (MTT) that was developed by the Japan Diabetes Society specifically for Japanese patients with T2DM [16]. The results of the MTT show a strong correlation with those of glucose tolerance tests [16]. The purpose of this study is to evaluate whether a standard dose of sitagliptin (50 mg/day) after a meal could improve the impaired acute insulin response in Japanese patients with T2DM in a real-world setting.

\section{METHODS}

\section{Subjects}

Twenty-one outpatients with T2DM participated in this study at Tottori University Hospital. T2DM was diagnosed based on the criteria of the Japan Diabetes Society [17]. Patients were eligible if their HbA1c was $6.0-9.0 \%$. These patients were divided into sitagliptin group and control group. This study was a prospective, open-label, non-randomized, clinical study. The patients were consecutively assigned to the control group and the sitagliptin group where the first 10 patients were assigned to the control group and the next 11 patients were assigned to the sitagliptin group. Patients in the sitagliptin group administered sitagliptin at a dose of $50 \mathrm{mg} /$ day once daily after breakfast throughout the treatment period. Patients with pancreatic disease, liver disease, renal failure (estimated Glomerular Filtration Rate $<30 \mathrm{~mL} /$ $\min / 1.73 \mathrm{~m}^{2}$ ), or those taking diabetogenic medications such as corticosteroids were excluded from this study. The duration of diabetes and presence of diabetic microangiopathy were retrieved from the patients' medical records. The adverse events were monitored by evaluating liver function, amylase, renal function, common blood count, and hypoglycemic events and abdominal symptoms, and so on. The primary endpoint of the study was the insulinogenic index.

This study was approved by the Ethics Committee of the Faculty of Medicine, Tottori University. All procedures followed were in accordance with the ethical standards of the responsible committee on human experimentation (institutional and national) and with the Helsinki Declaration of 1975, as revised in 2000 and 2008. Informed consent was obtained from all patients for being included in the study. This study was registered with the University hospital Medical Information Network (identifier: UMIN000011189).

\section{Meal Tolerance Test}

After fasting for at least $12 \mathrm{~h}$, the participants visited the hospital in the morning and consumed a test meal prepared by the Japan Diabetes Society (JANEF E460F18: total calories $460 \mathrm{kcal}$, carbohydrates $56.5 \mathrm{~g}$, fat $18.0 \mathrm{~g}$, protein $18.0 \mathrm{~g}$; Kewpie corporation, Tokyo, Japan) [16]. Patients consumed the test meal 
within $15 \mathrm{~min}$, and took 50-mg sitagliptin after the meal. Plasma glucose and insulin were measured at $0 \mathrm{~min}$ (fasting), and 30, 60, 120, and $180 \mathrm{~min}$ after the test meal. Plasma glucose levels were measured using the Hexokinase/ Glucose-6-Phosphate Dehydrogenase method [18]. Plasma insulin levels were measured using a human chemiluminescent immunoassay kit (Kyowa Medix, Tokyo, Japan). Plasma insulin was defined as immunoreactive insulin (IRI). This MTT is a well-established method that has been used in our hospital in prior studies [19-21].

HbA1c (JDS, Japan Diabetes Society) was measured by high-performance liquid chromatography. However, HbA1c (JDS) values are about $0.4 \%$ lower than those of NGSP values, which are the global standard, although measurements of HbAlc in Japan are well calibrated with certified serial reference materials from Lot 1 to Lot 4 using a high resolution ion-exchange HPLC method (KO500). HbA1c (JDS) was converted to National Glycohemoglobin Standardization Program (NGSP) values using the following officially certified equation: NGSP $(\%)=1.02 \times$ JDS $(\%)+0.25 \%$ [22]. The reverse equation is: JDS $(\%)=0.980 \times \operatorname{NGSP}(\%)-0.245 \%$.

\section{Calculation of Insulin Secretion and Resistance Indices}

The insulinogenic index was calculated as previously described [23]: Insulinogenic index $=$ $\{$ insulin (pmol/L) at $30 \mathrm{~min}]-[$ insulin $(\mathrm{pmol} /$ $\mathrm{L})$ at $0 \mathrm{~min}]\} /\{$ gglucose $(\mathrm{mmol} / \mathrm{L})$ at $30 \mathrm{~min}$ ] - glucose $(\mathrm{mmol} / \mathrm{L})$ at $0 \mathrm{~min}]\}$. An impaired acute insulin response was defined as an insulinogenic index of $<43.2$ [24] $(<0.4$ based on glucose in $\mathrm{mg} / \mathrm{dL}$ and insulin in $\mu \mathrm{U} / \mathrm{mL}$ ). Homeostasis model assessment of insulin resistance (HOMA-IR) was calculated as previously described [25]: HOMA-IR $=$ FPG $(\mathrm{mmol} / \mathrm{L})] \times[$ fasting IRI $(\mathrm{F}-\mathrm{IRI} ; \mathrm{pmol} / \mathrm{L})] / 135$. The insulin sensitivity index (ISI) was calculated as previously described [26]: ISI $=10,000 / \sqrt{ }\{[$ FPG $(\mathrm{mmol} / \mathrm{L}) \times$ fasting plasma insulin $(\mathrm{pmol} / \mathrm{L})] \times$ [mean glucose $\times$ mean insulin during the MTT] $\}$.

\section{Statistical Analysis}

Data are expressed as mean \pm standard deviation. The area under the curve (AUC) was calculated according to the trapezoidal rule. We analyzed the variables using the KolmogorovSmirnov test. Because ISI and F-IRI showed nonnormal distributions, the variables F-IRI, HOMA-IR, ISI, and insulinogenic index were analyzed using non-parametric tests. The other variables were normally distributed. The baseline characteristics were compared between the two groups using unpaired Student's $t$ test. F-IRI, HOMA-IR, ISI, and insulinogenic index were compared between the two groups using the Mann-Whitney $U$ test. The proportions of patients with microangiopathy were compared using Fisher's exact test. Differences in continuous variables were compared between before and 3 months of treatment using paired Student's $t$ test, except for the changes in F-IRI, HOMA-IR, ISI, and insulinogenic index, which were analyzed using the Wilcoxon rank-sum test. The changes in continuous variables from before to 3 months of treatment were compared between the two groups using unpaired Student's $t$ test, except for F-IRI, HOMA-IR, ISI, and insulinogenic index, which were compared using the MannWhitney $U$ test. Values of $P<0.05$ were considered statistically significant. SPSS software version 15.0 (SPSS, Chicago, IL, USA) was used for all analyses. 


\section{RESULTS}

\section{Patient Characteristics}

The mean age of the patients in sitagliptin group was 67.4 years, the mean BMI was $23.0 \mathrm{~kg} / \mathrm{m}^{2}$, the mean FPG was $8.05 \mathrm{mmol} / \mathrm{L}$ (144.8 $\mathrm{mg} / \mathrm{dL})$, the mean HbA1c was $7.73 \%$, and the mean insulinogenic index was 20.1 (Table 1). There were eight males and three females in sitagliptin group, and seven males and three females in the control group. The mean age of the patients in the control group was 64.2 years, the mean BMI was $24.4 \mathrm{~kg} / \mathrm{m}^{2}$, the mean FPG was $8.12 \mathrm{mmol} / \mathrm{L}(146.3 \mathrm{mg} / \mathrm{dL})$, the mean HbA1c was $7.20 \%$, and the mean insulinogenic index was 21.8 (Table 1). In the sitagliptin group, four patients were on diet therapy alone and seven were using oral hypoglycemic agents (OHAs), including sulfonylurea (7 patients), $\alpha$-glucosidase inhibitors (3), biguanides (3), and thiazolidinediones (1). In the control group, two patients were on diet therapy alone and eight were using oral hypoglycemic agents (OHAs), including sulfonylurea (6 patients), a-glucosidase inhibitors (3), biguanides (4), thiazolidinediones (1). None of the patients in either group were using glinides or insulin. The duration of diabetes was 9.8 years in the sitagliptin group versus 7.7 years in the control group. In each group, seven patients had diabetic neuropathy, and two patients had simple diabetic retinopathy. Two patients also had diabetic nephropathy, the two patients in the sitagliptin group had macroalbuminurea, and the two patients in the control group had microalbuminurea. There were no significant differences in any of the baseline characteristics between the sitagliptin and control groups. The adverse events were not detected in the research period.
The mean FPG did not change significantly from baseline to 3 months of treatment in the sitagliptin group (from 8.05 to $7.26 \mathrm{mmol} / \mathrm{L}$, $P=0.09$ ) and the control group (from 8.12 to $7.88 \mathrm{mmol} / \mathrm{L}, \quad P=0.29$ ) (Table 1 ). The mean HbA1c decreased significantly in the sitagliptin group (from 7.73 to $6.86 \%, P<0.001$ ), but not in the control group (from 7.20 to $7.37 \%$, $P=0.20)$. There were no significant changes in body weight or BMI, and lipid profile in either group.

The mean change in FPG from baseline to 3 months was not significantly different between the sitagliptin and control group $(-0.79$ vs. $\quad-0.25 \mathrm{mmol} / \mathrm{L}, \quad P=0.28)$, but HbA1c decreased significantly in the sitagliptin group compared with the control group ( $-0.88 \%$ vs. $+0.17 \%, P<0.0005$; Table 1$)$. The changes in body weight, BMI, and lipid profile were not significantly different between the two groups.

\section{Meal Tolerance Test}

There were no significant differences in glucose levels and insulin responses between the two groups at baseline. After 3 months of treatment, the plasma glucose levels at 60, 120, and $180 \mathrm{~min}$ were significantly decreased in the sitagliptin (Fig. 1a), whereas no significant changes were observed in the control group (Fig. 1b). The plasma insulin levels at 0 and $30 \mathrm{~min}$ were significantly increased by sitagliptin (Fig. 2a), whereas no changes in plasma insulin were found in the control group (Fig. 2b).

The insulinogenic index increased significantly from baseline to 3 months of treatment in the sitagliptin group (from 20.1 to $36.9, P<0.05$ ) (Table 1 ), but not in the control group (from 21.8 to 22.0, $P=0.96$ ). Although HOMA-IR increased significantly in 


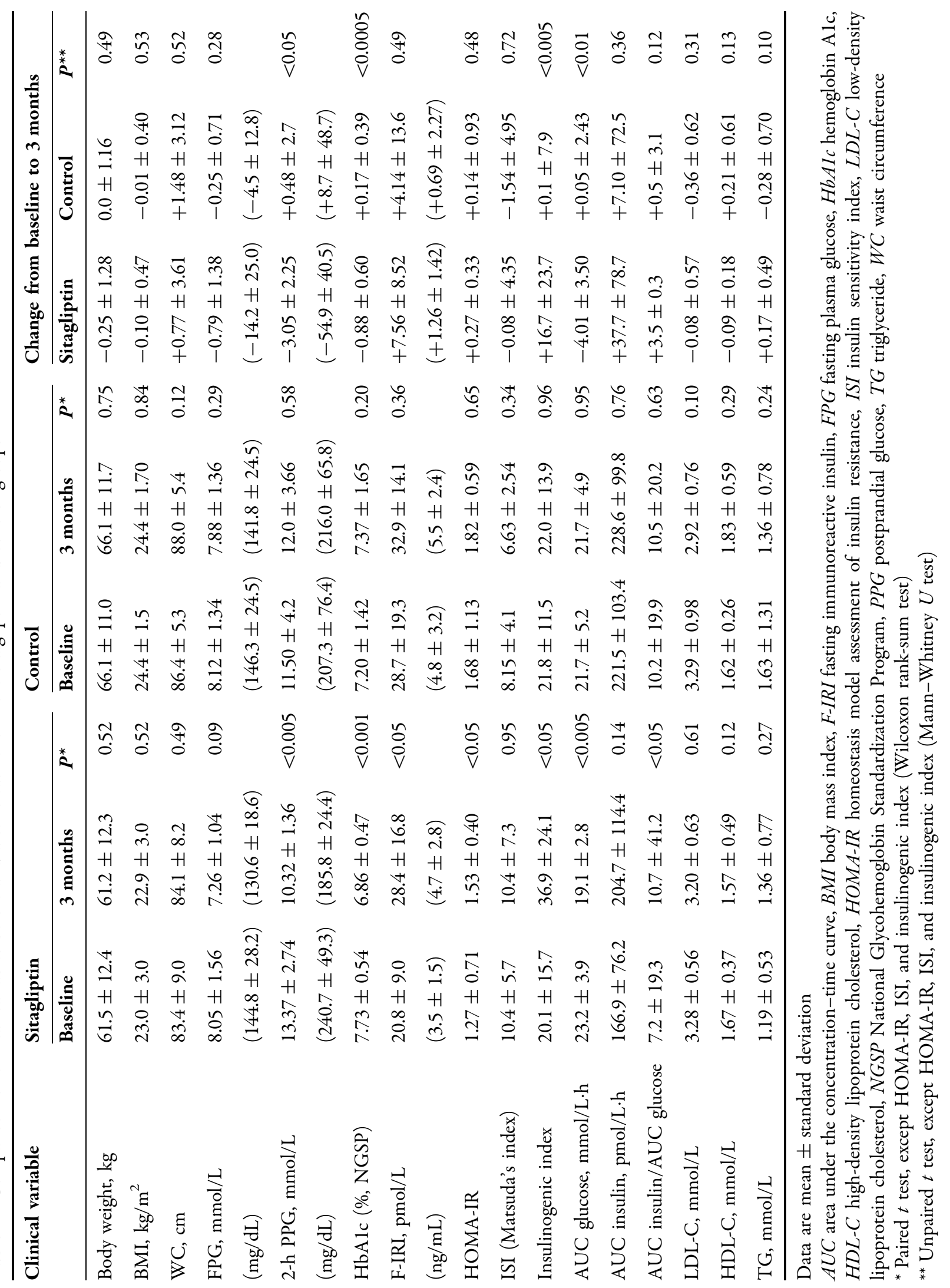



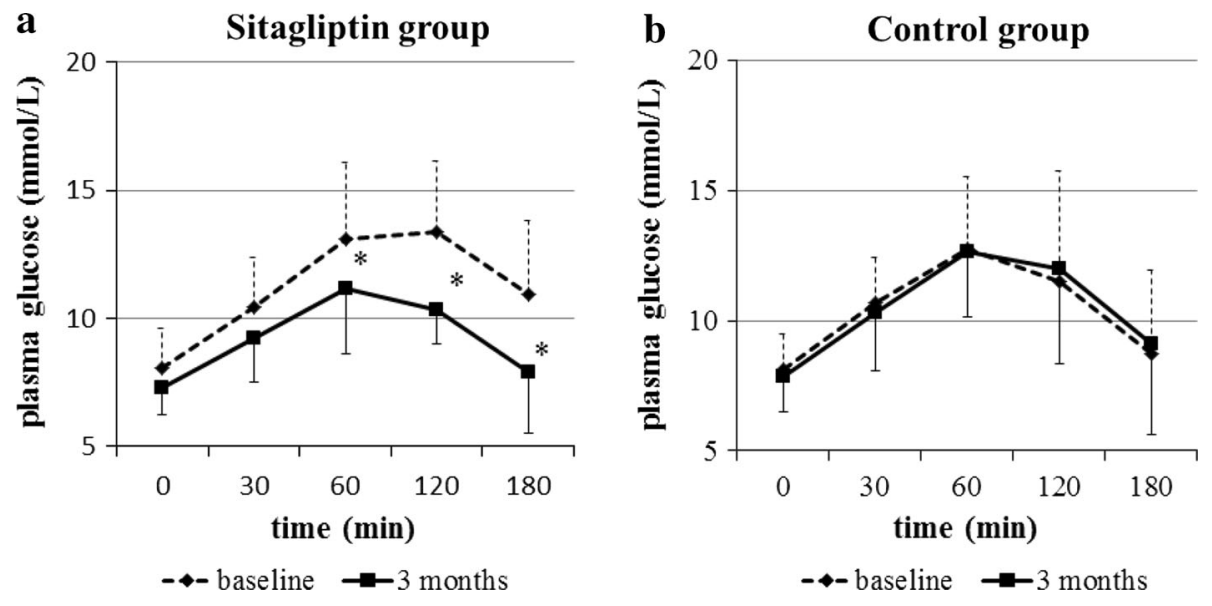

Fig. 1 Plasma glucose responses during the meal tolerance test. The plasma glucose levels at 60, 120, and 180 min were significantly decreased in the sitagliptin group (a), but not in the control group $(\mathbf{b}) .{ }^{*} P<0.05$ vs. baseline (paired $t$ test)

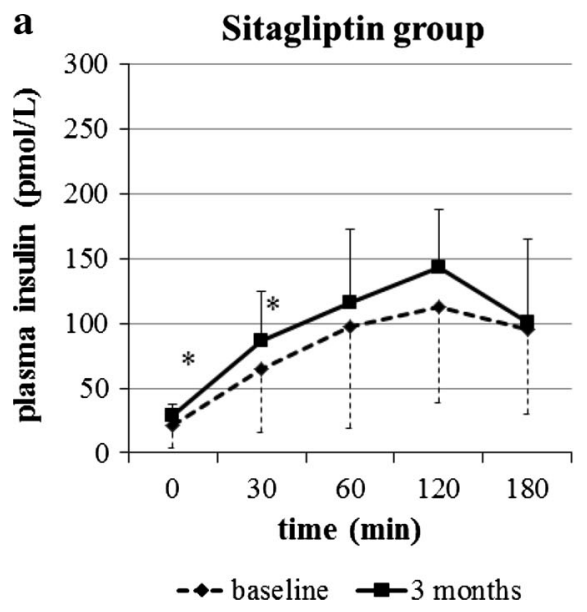

Fig. 2 Plasma insulin responses during the meal tolerance test. Plasma insulin levels at 0 and 30 min were significantly increased in the sitagliptin group (a), but not in the control

the sitagliptin group (from 1.27 to 1.53 , $P<0.05$ ), the ISI did not (from 10.4 to 10.4 , $P=0.95)$. HOMA-IR and ISI did not significantly change in the control group (HOMA-IR from 1.68 to $1.82, P=0.65$; ISI from 8.15 to $6.63, P=0.34$ ). The area under the concentration-time curve (AUC) for glucose decreased significantly in the sitagliptin, but did not change in the control group. The AUC for insulin did not change significantly in either



group (b). ${ }^{*} P<0.05$ vs. baseline [paired $t$ test, except for fasting plasma insulin (Wilcoxon rank-sum test)]

group. The AUC for insulin/AUC for glucose ratio increased significantly in the sitagliptin group, but not in the control group (Table 1).

The change in the insulinogenic index from baseline to 3 months was significantly greater in the sitagliptin group than in the control group (+16.7 vs. $+0.1, P<0.005$; Table 1$)$. However, the changes in HOMA-IR and ISI were not significantly different between the two groups. Although the AUC for glucose decreased 
significantly in the sitagliptin group compared with the control group, the AUC for insulin and the AUC for insulin/AUC for glucose were not significantly different between the two groups.

\section{DISCUSSION}

In this study, treatment with $50 \mathrm{mg} /$ day sitagliptin after a meal for 3 months significantly reduced postprandial glucose levels and increased the insulinogenic index measured during MTTs. These results suggest that sitagliptin improved the acute insulin response in a cohort of Japanese patients with T2DM. In prior studies, DPP-4 inhibitors mainly improved insulin resistance in obese populations, but did not improve the acute insulin response [5-8]. The mean BMIs of patients in these earlier studies ranged from 27.5 to $33.2 \mathrm{~kg} / \mathrm{m}^{2}$. A recent study revealed that sitagliptin improved the insulinogenic index determined during an OGTT in Korean patients [27]. The mean BMI of patients in that study was $25.3 \mathrm{~kg} / \mathrm{m}^{2}$. These results imply that DPP-4 inhibitors improve the acute insulin response in Asian patients with T2DM. The mean BMI was $23.0 \mathrm{~kg} / \mathrm{m}^{2}$ for the sitagliptin group in our study.

The diabetes epidemic in Asia is characterized by the onset of diabetes at lower BMI levels and younger ages compared with Caucasian populations [28]. Although the mean BMI is still relatively low in Asian populations, abdominal or central obesity is also highly prevalent, resulting in a widespread "metabolically obese" phenotype. Notable, a meta-analysis revealed that DPP-4 inhibitors lowered $\mathrm{HbA1c}$ to a greater extent in studies with $\geq 50 \%$ Asian participants (weighted mean difference $-0.92 \%$; $95 \% \mathrm{CI}-1.03,-0.82$ ) than in studies with $<50 \%$ Asian participants (weighted mean difference $-0.65 \%$; $95 \%$ CI
$-0.69,-0.60)$ [29]. The meta-analysis found no correlation between BMI and the reduction in HbA1c in studies where the mean BMI was $\geq 30 \mathrm{~kg} / \mathrm{m}^{2}$, but BMI was significantly correlated with the reduction in HbA1c in studies where the mean BMI was $<30 \mathrm{~kg} / \mathrm{m}^{2}$. There were no differences in the change in body weight from baseline between the Asian- and the non-Asiandominant studies, which suggest that the baseline BMI might influence the glucoselowering effects of DPP-4 inhibitors. These results suggest that a lower BMI at baseline predicts at greater response to a DPP-4 inhibitor. Accordingly, the difference in BMI among ethnic groups may contribute to the differences in the glucose-lowering response to DPP-4 inhibitors. Another meta-analysis revealed that DPP-4 inhibitors achieved a mean reduction in $\mathrm{HbA} 1 \mathrm{c}$ of $-0.65 \%$ in nonJapanese randomized controlled trials $(n=55)$, and a greater reduction of $-1.67 \%$ in Japanese randomized controlled trials $(n=7)$ [30]. The authors suggested that there may be pharmacogenetic or cultural/lifestyle differences that may contribute to the greater reduction in HbA1c in Japanese patients than in studies performed in other countries. A recent article reported that DPP4, a novel adipokine, has a higher release from visceral adipose tissue that is particularly pronounced in obese and insulin-resistant patients [31]. DPP4 from adipose tissue explants was higher in visceral adipose tissue than in subcutaneous adipose tissue in both lean and obese patients, with obese patients displaying higher DPP4 release than lean controls. These results might be able to explain that DPP4 inhibitor is effective for non-obese patients. Our results also suggest that sitagliptin might be effective in non-obese Japanese and other Asian patients with T2DM.

It has been proposed that the restoration of the early phase of insulin release and 
postprandial hyperglycemia has important implications on the improvements of metabolic control and reducing the risk of macrovascular complications [32]. Our results suggest that sitagliptin contributes to improvements in metabolic control and a reduction in cardiovascular risk in patients with T2DM. However, a recent study indicated that the top quartile of the Matsuda ISI was negatively associated with coronary artery calcification, but the insulinogenic index was not associated with coronary artery calcification [33]. The effects of treating impaired early phase insulin secretion and postprandial hyperglycemia on macroangiopathy are still controversial, and more studies are needed in this field. Moreover, in Japan, approximately half of all patients with diabetes have a genetic predisposition to the disease, and insulin secretion is often impaired in lean patients with diabetes mellitus [9, 10]. Additionally, Japanese and Asian patients often show reduced $\beta$-cell function $[11,12]$. However, a recent study indicated that disposition indices were similar in Japanese and Caucasian patients, and that the differences in insulin sensitivity and $\beta$-cell responses between Japanese and Caucasian patients are mainly explained by differences in body composition [34]. Although further studies are needed to investigate these issues, it is notable that a large proportion of Japanese patients exhibit impaired acute insulin responses. In our study, sitagliptin significantly reduced $\mathrm{HbA1c}$ and the AUC for glucose but not AUC for insulin and lipid profile, suggesting that a reduction in glucotoxicity helped to improve insulin secretion. Treatment with sitagliptin also had a significant effect on HOMA-IR, but not on ISI. We suspect that the increase in HOMA-IR was due to an increase in insulin secretion rather than worsening of insulin resistance. The peak concentration time $\left(T_{\max }\right)$ for $50 \mathrm{mg} /$ day sitagliptin in Japanese patients is $2.0 \mathrm{~h}$ when taken after a meal and $2.5 \mathrm{~h}$ when taken before a meal [15]. Moreover, the half-life $\left(t_{1 / 2}\right)$ of sitagliptin is $12.3 \mathrm{~h}$ when taken after a meal and $12.2 \mathrm{~h}$ when taken before a meal [15]. Therefore, we consider that the insulin responses at 0 and $30 \mathrm{~min}$ were due to the acute and chronic effects of sitagliptin. Although we must be careful when interpreting these findings, our results demonstrate that sitagliptin is effective in Japanese patients with T2DM by reducing postprandial hyperglycemia in particular.

Our study had several limitations, including the small number of patients. Because only 11 patients were treated with sitagliptin, our results require confirmation in a larger study. Furthermore, because our study was small and was conducted in an open-label, nonrandomized manner, it is difficult to exclude the risk of bias. Design of assignment of patients may have influenced the tendency of difference of postprandial glucose, HbA1c, and F-IRI, although the difference was not significant. The sample size of our study was very small because of the limited numbers of potentially eligible patients at our clinic. Accordingly, the results of this study should be confirmed in a larger study with an appropriate power calculation. The future confirmatory study should involve a blinded, randomized controlled design. Therefore, we added 'a small scale real-world study' in the title. Another potential limitation is that we did not measure incretins or glucagon. However, it is difficult to measure these hormones because they are very unstable and are rapidly degraded. The Japan Diabetes Society established a working group to standardize the 
measurement of incretins [35]. They recently proposed that samples should be extracted using a specific procedure to provide more accurate values, and they are currently developing a method to standardize and improve the accuracy of measuring of incretin levels [35]. In lieu of these recommendations, it is very difficult to measure incretin levels. Nevertheless, we hope to measure these hormones in future studies. It is possible that the different medications used by the subjects modified the insulin response in the MTT. Many of the patients were treated with a sulfonylurea, which might affect the insulin response [36]. However, in a recent study, treatment with sitagliptin for 60 weeks decreased $\mathrm{HbA} 1 \mathrm{c}$ by $-0.9 \%(-10 \mathrm{mmol} / \mathrm{mol})$ when used in combination with metformin and by $-1.0 \%(-11 \mathrm{mmol} / \mathrm{mol})$ in combination with metformin and glimepiride [37]. These results suggest that treatment with a sulfonylurea did not markedly affect the reduction in HbA1c during treatment with sitagliptin. Because the insulinogenic index was originally derived from the results of OGTTs, it may not be appropriate for assessing acute insulin secretion during MTTs. Indeed, in one study, the insulinogenic index was higher during MTTs than during OGTTs [38]. However, another study found no difference in the insulinogenic index between OGTTs and MTTs [15]. Considering the results of these earlier studies, we defined impaired acute insulin secretion during MTT as an insulinogenic index of $<43.2$. It was also reported that fat intake enhances GLP-1 secretion [39]. Therefore, it is possible that the effects of sitagliptin were augmented by the fat content of the mixed meal used in this study. Despite these limitations, we think that our study may aid routine clinical treatment of Japanese and other Asian patients with T2DM.

\section{CONCLUSION}

Treatment with $50 \mathrm{mg} /$ day sitagliptin after a meal for 3 months improved the acute insulin response and suppressed postprandial hyperglycemia measured during MTTs. Whereas the study is rather small and the design is suboptimal as it is not randomized and not blinded, these results suggest that sitagliptin may be effective in Japanese patients with T2DM, many of whom display impaired acute insulin responses.

\section{ACKNOWLEDGMENTS}

This manuscript was edited by medical writing assistance, Nicholas. D. Smith, Edanz editing. This study was supported by a Tottori University Hospital Research Grant. No funding or sponsorship was received for the medical writing assistance and article processing charges of this article. We thank Ms. Maki Kameda and Ms. Yoshiko Oda for their technical assistance. This work was carried out at Tottori University Faculty of Medicine, Tottori, Japan. TO and YF participated in the design of the study and performed the statistical analysis. KS, RN, HS, NY, KM, SI, and HO collected the data. MK, ST, and KY conceived the study, participated in its design and coordination, and helped to draft the manuscript. All named authors meet the ICMJE criteria for authorship for this manuscript, take responsibility for the integrity of the work as a whole, and have given final approval for the version to be published.

Conflict of interest. Tsuyoshi Ohkura, Youhei Fujioka, Keisuke Sumi, Risa Nakanishi, Hideki Shiochi, Naoya Yamamoto, Kazuhiko 
Matsuzawa, Shoichiro Izawa, Hiroko Ohkura, Masahiko Kato, Shin-ichi Taniguchi, and Kazuhiro Yamamoto declare no conflict of interest.

Compliance with ethics guidelines. This study was approved by the Ethics Committee of the Faculty of Medicine, Tottori University. All procedures followed were in accordance with the ethical standards of the responsible committee on human experimentation (institutional and national) and with the Helsinki Declaration of 1975, as revised in 2000 and 2008. Informed consent was obtained from all patients for being included in the study. This study was registered with the University hospital Medical Information Network (identifier: UMIN000011189).

Open Access. This article is distributed under the terms of the Creative Commons Attribution Noncommercial License which permits any noncommercial use, distribution, and reproduction in any medium, provided the original author(s) and the source are credited.

\section{REFERENCES}

1. DeFronzo RA. Lilly lecture 1987. The triumvirate beta-cell, muscle, liver. A collusion responsible for NIDDM. Diabetes. 1987;1988(37):667-87.

2. Mest HJ, Mentlein R. Dipeptidyl peptidase inhibitors as new drugs for the treatment of type 2 diabetes. Diabetologia. 2005;48:616-20.

3. Ahren B, Schmitz O. GLP-1 receptor agonists and DPP-4 inhibitors in the treatment of type 2 diabetes. Horm Metab Res. 2004;36:867-76.

4. Ahren B, Holst JJ, Martensson H, Balkan B. Improved glucose tolerance and insulin secretion by inhibition of dipeptidyl peptidase IV in mice. Eur J Pharmacol. 2000;404:239-45.

5. Ahren B, Landin-Olsson M, Jansson PA, Svensson M, Holmes D, Schweizer A. Inhibition of dipeptidyl peptidase-4 reduces glycemia, sustains insulin levels, and reduces glucagon levels in type 2 diabetes. J Clin Endocrinol Metab. 2004;89: 2078-84.

6. Herman GA, Bergman A, Stevens C, et al. Effect of single oral doses of sitagliptin, a dipeptidyl peptidase-4 inhibitor, on incretin and plasma glucose levels after an oral glucose tolerance test in patients with type 2 diabetes. J Clin Endocrinol Metab. 2006;91:4612-9.

7. Aaboe K, Knop FK, Vilsbøll T, et al. Twelve weeks treatment with the DPP-4 inhibitor, sitagliptin, prevents degradation of peptide YY and improves glucose and non-glucose induced insulin secretion in patients with type 2 diabetes mellitus. Diabetes Obes Metab. 2010;12:323-33.

8. Azuma K, Rádiková Z, Mancino J, et al. Measurements of islet function and glucose metabolism with the dipeptidyl peptidase 4 inhibitor vildagliptin in patients with type 2 diabetes. J Clin Endocrinol Metab. 2008;93:459-64.

9. Kadowaki T, Miyake Y, Kajinuma H. Risk factors for worsening to diabetes in subjects with impaired glucose tolerance. Diabetologia. 1984;26:44-9.

10. Kadowaki $T$, Yoshinaga $H$. Risk factors for the development of non-insulin-dependent diabetes mellitus (NIDDM) in Japan. Diabetes Res Clin Pract. 1994;24:123-7.

11. Fujimoto WY. Overview of non-insulin dependent diabetes mellitus (NIDDM) in different population groups. Diabet Med. 1996;13:7-10.

12. Kodama K, Tojjar D, Yamada S, Toda K, Patel CJ, Butte AJ. Ethnic differences in the relationship between insulin sensitivity and insulin response: a systematic review and meta-analysis. Diabet Care. 2013;36:1789-96.

13. Nonaka K, Kakikawa T, Sato A, et al. Efficacy and safety of sitagliptin monotherapy in Japanese patients with type 2 diabetes. Diabet Res Clin Pract. 2008;79:291-8.

14. Iwamoto $\mathrm{Y}$, Taniguchi $\mathrm{T}$, Nonaka $\mathrm{K}$, et al. Doseranging efficacy of sitagliptin, a dipeptidyl peptidase-4 inhibitor, in Japanese patients with type 2 diabetes mellitus. Endocr J. 2010;57:383-94.

15. Herman GA, Mistry GC, Yi B, Bergman AJ, Wang AQ, Zeng W, Chen L, Snyder K, Ruckle JL, Larson PJ, Davies MJ, Langdon RB, Gottesdiener KM, Wagner JA. Evaluation of pharmacokinetic parameters and dipeptidyl peptidase-4 inhibition following single doses of sitagliptin in healthy, young Japanese males. Br J Clin Pharmacol. 2011;71: 429-36. 
16. Yoshino $G$, Tominaga $M$, Hirano $T$, et al. The test meal A: a pilot model for the international standard of test meal for an assessment of both postprandial hyperglycemia and hyperlipidemia. J Jpn Diabetes Soc. 2006;49:361-71.

17. Kuzuya T, Nakagawa S, Satoh J, et al. Report of the Committee on the classification and diagnostic criteria of diabetes mellitus. Diabet Res Clin Pract. 2002;55:65-85.

18. Sacks DB. Carbohydrates. In: Burtis C, Ashwood E editors. Tietz textbook of clinical chemistry, 3rd ed. Philadelphia: WB Saunders; 1999. p. 750-808.

19. Ohkura T, Shiochi H, Fujioka Y, et al. 20/(fasting C-peptide $\mathrm{x}$ fasting plasma glucose) is a simple and effective index of insulin resistance in patients with type 2 diabetes mellitus: a preliminary report. Cardiovasc Diabetol. 2013;12:21.

20. Sumi K, Ohkura T, Yamamoto N, et al. Long-term miglitol administration suppresses postprandial glucose-dependent insulinotropic polypeptide secretion. Diabetol Int. 2013;4:190-6.

21. Ohkura T, Inoue K, Fujioka Y, et al. The proinsulin/ insulin (PI/I) ratio is reduced by postprandial targeting therapy in type 2 diabetes mellitus: a small-scale clinical study. BMC Res Notes. 2013;6:453.

22. Kashiwagi A, Kasuga M, Araki E, et al. International clinical harmonization of glycated hemoglobin in Japan: from Japan Diabetes Society to National Glycohemoglobin Standardization Program values. J Diabetes Invest. 2012;3:39-40.

23. Seltzer HS, Allen EW, Herron AL Jr, Brennan MT. Insulin secretion in response to glycemic stimulus: relation of delayed initial release to carbohydrate intolerance in mild diabetes mellitus. J Clin Invest. 1967;46:323-35.

24. Matsuda A, Kuzuya T. The prevalence of low insulin responders to oral glucose load among groups with various patterns of family history of diabetes. Diabet Med. 1996;13:59-62.

25. Matthews DR, Hosker JP, Rudenski AS, Naylor BA, Treacher DF, Turner RC. Homeostasis model assessment: insulin resistance and beta-cell function from fasting plasma glucose and insulin concentrations in man. Diabetologia. 1985;28:412-9.

26. Matsuda M, DeFronzo RA. Insulin sensitivity indices obtained from oral glucose tolerance testing: comparison with the euglycemic insulin clamp. Diabet Care. 1999;22:1462-70.

27. Lim S, An JH, Shin $\mathrm{H}$, et al. Factors predicting therapeutic efficacy of combination treatment with sitagliptin and metformin in type 2 diabetic patients: the COSMETIC study. Clin Endocrinol (Oxf). 2012;77:215-23.

28. Hu FB. Globalization of diabetes: the role of diet, lifestyle, and genes. Diabet Care. 2011;34:1249-57.

29. Kim YG, Hahn S, Oh TJ, Kwak SH, Park KS, Cho YM. Differences in the glucose-lowering efficacy of dipeptidyl peptidase-4 inhibitors between Asians and non-Asians: a systematic review and metaanalysis. Diabetologia. 2013;56:696-708.

30. Park H, Park C, Kim Y, Rascati KL. Efficacy and safety of dipeptidyl peptidase-4 inhibitors in type 2 diabetes: meta-analysis. Ann Pharmacother. 2012;46:1453-69.

31. Sell H, Blüher $M$, Klöting $N$, et al. Adipose dipeptidyl peptidase- 4 and obesity: correlation with insulin resistance and depot-specific release from adipose tissue in vivo and in vitro. Diabet Care. 2013;36:4083-90.

32. Del Prato S, Tiengo A. The importance of first-phase insulin secretion: implications for the therapy of type 2 diabetes mellitus. Diabetes Metab Res Rev. 2001;17:164-74.

33. Mulvey CK, McNeill AM, Girman CJ, et al. Differential associations of oral glucose tolerance test-derived measures of insulin sensitivity and pancreatic $\beta$-cell function with coronary artery calcification and microalbuminuria in type 2 diabetes. Diabet Care. 2014;37:124-33.

34. Møller JB, Pedersen M, Tanaka H, et al. Body composition is main determinant for the difference in type 2 diabetes pathophysiology between Japanese and Caucasians. Diabet Care. 2014;37:796-804.

35. Inagaki N, JDS/JADEC Committee for Standardized Incretin Measurement. Guideline for Incretin Measurement. http://www.jds.or.jp/uploads/photos/ 786.pdf. Accessed May 16, 2014.

36. Williams-Herman D, Engel SS, Round E, Johnson J, Golm GT, Guo H, Musser BJ, Davies MJ, Kaufman KD, Goldstein BJ. Safety and tolerability of sitagliptin in clinical studies: a pooled analysis of data from 10,246 patients with type 2 diabetes. BMC Endocr Disord. 2010;10:7.

37. Chung HS, Suh S, Kim MY, et al. Predictive factors of durability to sitagliptin: slower reduction of glycated hemoglobin, older age and higher baseline glycated hemoglobin. J Diabet Invest. 2014;5:51-9.

38. Rijkelijkhuizen JM, Girman CJ, Mari A, et al. Classical and model-based estimates of beta-cell function during a mixed meal vs. an OGTT in a 
population-based cohort. Diabet Res Clin Pract. 2009;83:280-8.

39. Gentilcore D, Chaikomin R, Jones KL, et al. Effects of fat on gastric emptying of and the glycemic, insulin, and incretin responses to a carbohydrate meal in type 2 diabetes. J Clin Endocrinol Metab. 2006;91:2062-7. 